\title{
Work-related musculoskeletal disorders among health care professionals.
}

\author{
Dr. Mokhlesur Rahman ${ }^{1}$, Dr. Abhijit Chowdhury ${ }^{2}$, Dr. Mohammad Shiblee Zaman ${ }^{3}$, \\ Dr. Nihar Sultana ${ }^{4}$, Dr. Mariam Binte Amin ${ }^{5}$, Dr. Md. Marroof Hossain ${ }^{6}$. \\ Received: 04 Jaunuary, 2017 Accepted: 09 February 2017
}

Abstract:

Musculoskeletal disorders (MSDs) represent a significant occupational problem among health care professionals; however, data on prevalence of work-related musculoskeletal disorders (WMSDs) are limited in our country for referencing. A descriptive cross sectional study was conducted during January to December 2016 among 160 health care professionals (doctors, nurses) working in a tertiary care hospital in Dhaka city. The aim of the study was to determine the prevalence, distribution and to find out the multiple risk factors that contribute to the development of WMSDs among the sample population. Data were collected with semi structured questionnaire based on a validated research instrument Standardized Nordic Questionnaire (SNQ) which records the prevalence of MSDs in terms of musculoskeletal symptoms (ache, pain, discomfort) in the preceding 12 months. The statisti$\mathrm{cal}$ analysis was done by using the SPSS software 21 version. The study result revealed that out of $160(100.0 \%)$ health care professionals 109 (68.1\%) had musculoskeletal pain or discomfort in the last 12 months and 51 (31.9\%) had not, and it was also found that 57 (61.3\%) doctors and 52 (77.6\%) nurses had musculoskeletal pain or discomfort in the last 12 months and the prevalence of work-related musculoskeletal disorders in different body region in the last 12 months, where more than 1 site involvement 46 (42.2\%) followed by neck 19 (17.4\%), shoulder 15 (13.8\%), lower back 13 (11.9\%), hips 8 (7.3\%), hand/fingers 5 (4.6\%). About the self reported risk factors among the health care professionals for WMSDs were found working the same position for long periods 48 (29.8\%), followed by treating excessive number of patients in a day 47 (29.1\%), inadequate training on injury prevention 25 (15.9\%), working awkward or cramped position18(11.6\%). There were no statistically significant association found in age and years of experience of the health care professionals with the WMSDs ( $p$ value .281, .083 respectively), but significant association found in sex and occupation of the health care professionals with WMSDs ( $p$ value $.045, .031$ respectively). As because a high proportion of health care professionals had WMSDs and they are on the risk for development of WMSDs, it can be recommended that education programmes on prevention and coping strategies for musculoskeletal disorders be made mandatory for health care professionals in order to reduce the rate of WMSDs among them and to promote efficiency in patient care.

Key words:

Musculoskeletal disorders, Health care professionals, Standardized Nordic Questionnaire.

1. MBBS,MPH,MHSM. Monash University, Australia.

2. Research Fellow, Centre for Clinical Epidemiology and Biostatistics, Hunter Medical Research Institute, The University of Newcastle, Australia.

3. Lecturer, Department of Biochemistry, Dhaka Medical College, Dhaka.

4. Assistant Professor, Department of Oral Anatomy and Physiology, Mandy Dental College, Dhaka; PhD Research Fellow (Bangladesh University of Professionals).

5. Honorary Medical Officer, Department of Medicine, Z.H. Sikder Women's Medical College and Hospital, Dhaka.

6. Dental Surgeon, Decent Dental Care, Mirpur, Dhaka.

Correspondence : Dr. Nihar Sultana, e-mail: nihard40@gmail.com, cell: 01712-843965 


\section{Introduction:}

Musculoskeletal disorders (MSDs) are described as disorders of the muscles, nerves, tendons, ligaments, joints, cartilage, or spinal discs. The term "work-related musculoskeletal disorders" (WMSDs) refers to MSDs that are made worse or longer lasting by work conditions. MSDs are some of the most important work-related problems currently reported. ${ }^{[1]}$ WMSDs are common among health care workers, with the nursing population that constitutes about $33 \%$ of the hospital workforce at particularly high risk and accounting for $60 \%$ of the reported occupational injuries. ${ }^{[5]}$ WMSDs are reported to significantly impact on quality of life, ${ }^{[2]}$ cause lost work time or absenteeism, increase work restriction, transfer to another job,,$^{[3,4,5]}$ or disability than any other group of diseases with a considerable economic toll on the individual, the organization and the society as a whole. ${ }^{[6,7,8]}$ Health care professionals (doctors \& nurses) are exposed to a range of work related risk factors that may result in various occupational diseases, of which musculoskeletal disorders (MSDs) are common. Fortunately, good ergonomic practices can drastically reduce the likelihood of severity of MSDs. A number of studies have found that the mechanisms leading to work-related musculoskeletal pain are multi-factorial. ${ }^{[9]}$ This pain can be attributed to numerous risk factors, including prolonged static postures, repetitive movements, suboptimal lighting, poor positioning, genetic predisposition, mental stress, physical conditioning, age and obesity. ${ }^{[10]}$ It is generally agreed that the physical posture of the health care professionals while providing care, should be such that all muscles are in a relaxed, well-balanced and neutral position. Postures outside of this neutral position for a prolonged period are likely to cause musculoskeletal discomfort. ${ }^{[1]]}$ Although several authors have reported the prevalence of WMSDs among health care providers in the developed populations, ${ }^{[3,4,5,7]}$ however, data on prevalence of WMSDs are limited in our country for referencing. This study sought to determine the prevalence and distribution of WMSDs among two different groups of health care professionals (doctors \& nurses) working in a tertiary care hospital in Dhaka city and to find out the multiple risk factors that contribute to the development of WMSDs.

\section{Materials and methods:}

This descriptive type of cross sectional study was conducted during the period January to December 2016, among two different groups of health care professionals (doctors, nurses) working in various clinical departments of a tertiary care hospital named National Institute of Traumatology \& Orthopedic Rehabilitation (NITOR) in Dhaka city. After obtaining ethical clearance from the Institutional Ethical Committee, through non probability sampling as convenient to the investigators 160 respondents were interviewed who had at least 5 years of working experiences in respective field and among them 93 were doctors and 67 were nurses. The health care professionals who are purely academicians, those with current musculoskeletal trauma, who had history of accident and those who refused to participate were excluded from the study. To determine the prevalence and distribution of WMSDs among health care professionals a validated research instrument Standardized Nordic Questionnaire $(\mathrm{SNQ})^{[19]}$ has been used, which records the prevalence of MSD in terms of musculoskeletal symptoms (ache, pain, discomfort) in the preceding 12 months. After developing the questionnaire which focused on the MSDs related variables according to the objectives of the study, a pilot study was performed on five health care professionals before commencing the study. Data analysis was carried out using the software SPSS 21 version to determine frequency distributions, means and proportions. Comparison of proportions was done by using Chi square test, value of less than 0.05 was considered to be statistically significant.

\section{Results:}

Table 1: Socio demographic characteristics of the health care professionals.

\begin{tabular}{|c|c|c|c|}
\hline \multicolumn{2}{|c|}{ Socio demographic characteristics } & Doctors & Nurses \\
\hline \multicolumn{2}{|l|}{ Age [in years, Mean $( \pm S D)]$} & $37.4( \pm 7.1)$ & $46.4( \pm 7.7)$ \\
\hline \multirow{2}{*}{$\begin{array}{l}\text { Height [in cm } \\
\text { Mean(SD)] }\end{array}$} & Male & $178.2( \pm 6.3)$ & $177.9( \pm 4.6)$ \\
\hline & Female & $165.1( \pm 5.9)$ & $162.4( \pm 3.8)$ \\
\hline \multirow{2}{*}{$\begin{array}{l}\text { Body mass index }\left[\mathrm{Kg} / \mathrm{m}^{2} \text {, }\right. \\
\text { Mean }( \pm \mathrm{SD})]\end{array}$} & Male & $26.9( \pm 3.8)$ & $26.5( \pm 3.1)$ \\
\hline & Female & $24.2( \pm 4.1)$ & $26.1( \pm 4.6)$ \\
\hline \multicolumn{2}{|c|}{ Years of experience $[$ Mean $( \pm S D)]$} & $18.4( \pm 10.1)$ & $19.4( \pm 7.6)$ \\
\hline \multicolumn{2}{|c|}{ Working hours per week $[$ Mean $( \pm S D)]$} & $42.9( \pm 7.1)$ & $49.4( \pm 6.3)$ \\
\hline
\end{tabular}

Table 1 shows the distribution of socio demographic characteristics of the health care professionals. The 
mean age of the doctors and nurses was $37.4( \pm 7.1)$ and $46.4( \pm 7.7)$ years respectively. The mean years of experience of the doctors and nurses was 18.4 $( \pm 10.1)$ and $19.4( \pm 7.6)$ years respectively. The mean working hours per week of the doctors and nurses was $42.9( \pm 7.1)$ and $49.4( \pm 6.3)$ hours respectively.

Table 2: Musculoskeletal pain or discomfort in the last 12 months among the health care professionals.

\begin{tabular}{|l|l|l|l|} 
Health care & \multicolumn{2}{|c|}{$\begin{array}{c}\text { Musculoskeletal pain/ discomfort } \\
\text { in the last 12 months }\end{array}$} & Total \\
\hline professionals & Present & Absent & \\
\hline Doctors & $57(61.3)$ & $36(38.7)$ & $93(100.0)$ \\
\hline Nurses & $52(77.6)$ & $15(22.4)$ & $67(100.0)$ \\
\hline Total & $109(68.1)$ & $51(31.9)$ & $\begin{array}{l}160 \\
(100.0)\end{array}$ \\
\hline
\end{tabular}

Table 2 shows out of $160(100.0 \%)$ health care professionals 109 (68.1\%) had musculoskeletal pain or discomfort in the last 12 months and 51 (31.9\%) had not.

Table 3: Prevalence of work-related musculoskeletal disorders in different body region in the last 12 months.

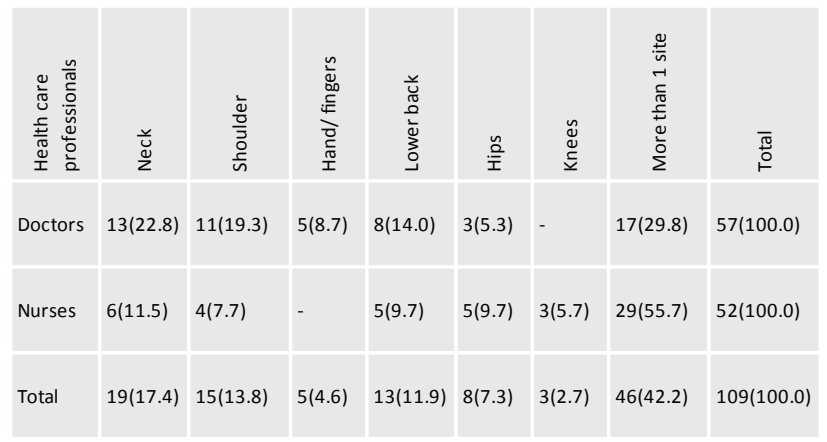

Table 3 shows among 109 (100.0\%) health care professionals who had work related musculoskeletal disorders $46(42.2 \%)$ had musculoskeletal symptoms more than 1 site in different body region. Among 57 $(100.0 \%)$ doctors and $52(100.0 \%)$ nurses, more than 1 site involvement of musculoskeletal symptoms had $17(29.8 \%)$ and $29(55.7 \%)$ respectively.

Table 4: Distribution of the respondents according to their statement about pain affecting their job or not.

\begin{tabular}{|l|l|l|l|}
\hline $\begin{array}{l}\text { Health care } \\
\text { professionals }\end{array}$ & $\begin{array}{c}\text { Pain } \\
\text { affecting the } \\
\text { job }\end{array}$ & $\begin{array}{c}\text { Pain not } \\
\text { affecting the }\end{array}$ & Total \\
\hline job & 16 (28.1) & $41(71.9)$ & $57(100.0)$ \\
\hline Nurses & $15(28.8)$ & $37(71.2)$ & $52(100.0)$ \\
\hline Total & $31(28.4)$ & $78(71.5)$ & $109(100.0)$ \\
\hline
\end{tabular}

Table 4 shows out of $109(100.0 \%)$ health care professionals $78(71.5 \%)$ mentioned pain not affecting the job and $31(28.4 \%)$ mentioned pain affecting the job.

Figure 1: Distribution of the health care professionals according to self reported risk factors for work-related musculoskeletal disorders. [ $n=160]$

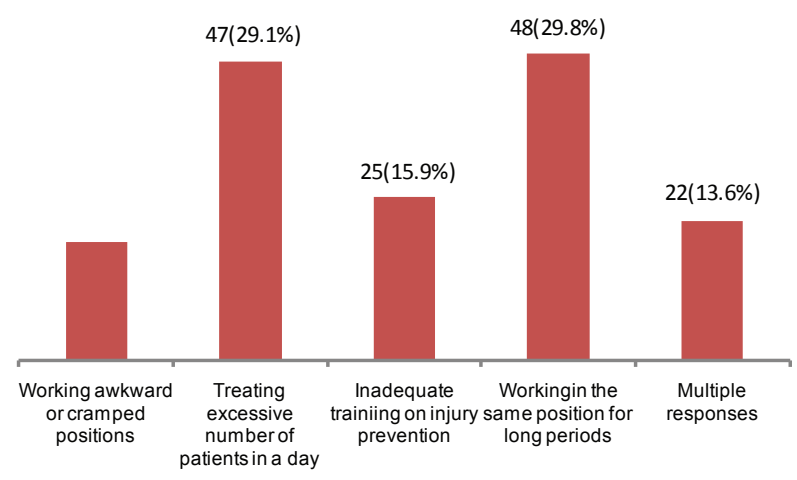

Figure 1 shows out of $160(100.0 \%)$ health care professionals $48(29.8 \%)$ mentioned about the risk factor working in same position for long period, 47(29.1\%), 25(15.9\%), 18(11.6\%) mentioned about the risk factors treating excessive number of patients in a day, inadequate training on injury prevention, working awkward or cramped positions respectively for work related musculoskeletal disorders. 
Table 5: Association between the predictors of work related musculoskeletal pain or discomfort in the last 12 months among the health care professionals.

\begin{tabular}{|c|c|c|c|c|c|}
\hline \multirow[t]{2}{*}{ 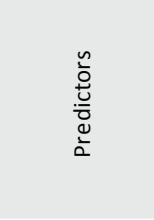 } & \multirow[t]{2}{*}{ 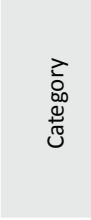 } & \multirow[t]{2}{*}{$\begin{array}{l}\bar{\pi} \\
\stackrel{0}{\circ}\end{array}$} & \multicolumn{2}{|c|}{$\begin{array}{l}\text { Work related } \\
\text { musculoskeletal pain } \\
\text { or discomfort in the } \\
\text { last } 12 \text { months }\end{array}$} & \multirow[t]{2}{*}{$\begin{array}{c}\text { p value } \\
\& \\
\times 2 \text { value }\end{array}$} \\
\hline & & & Present & Absent & \\
\hline \multirow{3}{*}{$\begin{array}{l}\text { Age group } \\
\text { (in years) }\end{array}$} & $22-33$ & $47(100.0 \%)$ & $32(68.1)$ & 15 (31.9) & \multirow{3}{*}{$\begin{array}{l}p=.281 \\
\chi 2=31.4\end{array}$} \\
\hline & $34-45$ & $72(100.0 \%)$ & $49(68.0)$ & $23(32.0)$ & \\
\hline & $>45$ & $41(100.0 \%)$ & $28(65.9)$ & $13(34.1)$ & \\
\hline \multirow{2}{*}{ Sex } & Male & $62(100.0 \%)$ & $48(77.4 \%)$ & $14(22.6 \%)$ & \multirow{2}{*}{$\begin{array}{l}p=.045 \\
\chi 2=5.97\end{array}$} \\
\hline & Female & $98(100.0 \%)$ & $61(62.2 \%)$ & $37(37.8 \%)$ & \\
\hline \multirow{4}{*}{$\begin{array}{l}\text { Years of } \\
\text { experience }\end{array}$} & $\leq 5$ & $52(100.0 \%)$ & $36(69.2 \%)$ & $16(30.8 \%)$ & \multirow{4}{*}{$\begin{array}{l}p=.083 \\
\chi 2=14.7\end{array}$} \\
\hline & $6-11$ & $13(100.0 \%)$ & $4(38.5 \%)$ & $8(61.5 \%)$ & \\
\hline & $12-17$ & $58(100.0 \%)$ & $47(81.0 \%)$ & $11(18.9 \%)$ & \\
\hline & $>17$ & $37(100.0 \%)$ & $21(56.7 \%)$ & $16(43.3 \%)$ & \\
\hline \multirow[b]{2}{*}{$\begin{array}{l}\text { Health care } \\
\text { professionals } \\
\text { occupation }\end{array}$} & Doctor & $93(100.0 \%)$ & $57(61.3 \%)$ & $36(38.7 \%)$ & \multirow[b]{2}{*}{$\begin{array}{l}p=.031 \\
\chi 2=17.3\end{array}$} \\
\hline & Nurse & $67(100.0 \%)$ & $52(77.6 \%)$ & $15(22.4 \%)$ & \\
\hline
\end{tabular}

Table 5 shows age group (in years) and years of experience of the health care professionals were not significantly associated with the work- related musculoskeletal pain or discomfort in the last 12 months (Since $p$ value more than .05). But significant association found in between sex and occupation of the health care professionals with the work-related musculoskeletal pain or discomfort in the last 12 months (Since $p$ value less than .05).

\section{Discussion:}

This descriptive type of cross sectional study was carried out with the aim to determine the prevalence and distribution of WMSDs among two different groups of health care professionals (doctors \& nurses) working in a tertiary care hospital in Dhaka city and to find out the multiple risk factors that contribute to the development of WMSDs. The socio demographic characteristics of the study result revealed that the mean age of the doctors and nurses was $37.4( \pm 7.1)$ and $46.4( \pm 7.7)$ years respectively, the mean years of experience of the doctors and nurses was $18.4( \pm 10.1)$ and $19.4( \pm 7.6)$ years respectively and the mean working hours per week of the doctors and nurses was $42.9( \pm 7.1)$ and 49.4 $( \pm 6.3)$ hours respectively. Out of $160(100.0 \%)$ health care professionals $109(68.1 \%)$ had musculoskeletal pain or discomfort in the last 12 months and 51 $(31.9 \%)$ had not, and it was also found that 57 $(61.3 \%)$ doctors and $52(77.6 \%)$ nurses had musculoskeletal pain or discomfort in the last 12 months, which was quite similar to the study finding ${ }^{[12]}$, where the prevalence and risk factors for low back pain among a variety of Turkish hospital workers, including nurses, physicians, physical therapists, technicians, secretaries, and hospital aides, in which the highest prevalence was reported by nurses $(77.1 \%)$. This study result showed the prevalence of work-related musculoskeletal disorders in different body region in the last 12 months, where more than 1 site involvement $46(42.2 \%)$ followed by neck $19(17.4 \%)$, shoulder $15(13.8 \%)$, lower back $13(11.9 \%)$, hips 8 (7.3\%), hand/fingers $5(4.6 \%)$ which was close to the study. ${ }^{[13,14]}$ In a comparative study ${ }^{[15]}$ more than 1 site involvement of MSDs among dentists were showed $35.0 \%$, which was consistent with the present study findings. Among 109 (100.0\%) health care professionals who had musculoskeletal pain or discomfort, almost three fourth $78(71.5 \%)$ mentioned that pain not affecting their job, where as 31(28.4\%) mentioned that pain affecting their job. About the self reported risk factors among the health care professionals for WMSDs were found working the same position for long periods 48 (29.8\%),followed by treating excessive number of patients in a day $47(29.1 \%)$, inadequate training on injury prevention $25(15.9 \%)$, working awkward or cramped position18(11.6\%)- which supports the findings of the study[14,16], where including these risk factors a number of risk factors has been showed. According to the study age group distribution had not significantly associated with WMSDs, which supports the study findings Tinubu et al. ${ }^{[17]}$, but is opposed to the study by Cromie et al. ${ }^{[18]}$ The sex of the respondents significantly associated with WMSDs like the study ${ }^{[14]}$, but dissimilar finding was observed in the study. ${ }^{[16]}$ Years of experience of the health care professionals were not significantly associated with the WMSDs which opposed the study findings. ${ }^{[13,14]}$ Again significant association found between occupation of the health care professionals with the WMSDs in Chi square test ( $p$ value.031), which also supports the study results. ${ }^{[14]}$ 


\section{Conclusion:}

Based on the findings of the present study, it can be concluded that a high proportion of health care professionals had WMSDs, and the affected site reported more than one body region, followed by neck, shoulder, lower back and other sites among them. In this study, working in the same positions for long periods, treating excessive number of patients in one day, inadequate training on injury prevention, working in awkward or cramped positions were found to be the commonly reported risk factors for the development of WMSDs. From the study it was observed nurses had the high prevalence of WRMSDs than doctors. Last but not the least it can be recommended that education programmes on prevention and coping strategies for musculoskeletal disorders be made mandatory for health care professionals in order to reduce the rate of WMSDs among them and to promote efficiency in patient care.

\section{References:}

1. Kakosy T, Németh L. Musculoskeletal disorders caused by hand-arm vibration. Global Occup Health Network. 2003;4(winter):3-6

2. Punnett L, Wegman DH: Work-related musculoskeletal disorders: the epidemiologic evidence and the debate. Journal of Electromyography and Kinesiology. 2004, 14: 13-23. 10.1016/j.jelekin.2003.09.015

3. Holder NI, Clark JM, DiBlasio JM, DiBlasio JM, Hughes CL, Schrpf JW, Harding L, Shepard KF: Cause, prevalence, and response to occupational musculoskeletal injuries reported by physical therapists and physical therapist assistants. Phys Ther. 1999, 79: 642-652

4. Aptel M, Aublet-Cuvelier A, Cnockaert JC: Work related musculoskeletal disorders of the upper limb. Joint Bone Spine. 2002, 69: 546-555. $10.1016 / S 1297-319 X(02) 00450-5$

5. Kilbom A: Editorial/Prevention of work-related musculoskeletal disorders in the workplace. Int J Ind Ergon. 1998, 21: 1-3. 10.1016/S0169-8141(97)00019-X

6. Badley EM, Rasooly I, Webster GK: Relative importance of musculoskeletal disorders as a cause of chronic health problems, disability, and health care utilization: Findings from the 1990 Ontario Health Survey. J Rheumatol. 1994, 3: $505-514$

7. Riihimaki H: Editorial: Hands up or back to work--future challenges in epidemiologic research on musculoskeletal diseases. Scand J Work Environ Health. 1995, 21: 401-403

8. Leijon MG, Hensing K, Alexanderson : Gender trends in sicklisting with musculoskeletal symptoms in a Swedish county during a period of rapid increase in sickness absence. Scand J Soc Med. 1998, 26 (3): 204-213

9. Stewart WF, Ricci JA, Chee E, Morganstein D, Lipton R. Lost productive time and cost due to common pain conditions in the US workforce. JAMA. 2003;290:2443-54

10. Smith DR, Wei N, Zhang YJ, Wang RS. Musculoskeletal complaints and psychosocial risk factors among physicians in mainland China. Int J Ind Ergon. 2006;36:599-603

11. Luxembourg: European Communities; 2004. European Communities Work and health in the EU, a statistical portrait

12. Karahan A, Kav S, Abbasoglu A, Dogan N. Low back pain: prevalence and associated risk factors among hospital staff. J Adv Nurs. 2009;65(3):516-524

13. Bolanle MST, Chidozie EM, Adewale LO, Ayodele AF. Work-Related Musculoskeletal Disorders among Nurses in Ibadan, South-west Nigeria: a cross-sectional survey. BMC Musculoskeletal Disorders201011:12

14. Sandul Y, Paramasivan R. Work-related musculoskeletal disorders among health care professionals: A cross-sectional assessment of risk factors in a tertiary hospital, India.2016

15. T Rambabu, K Suneetha. Prevalence of Work Related Musculoskeletal Disorders Among Physicians, Surgeons and Dentists: A Comparative Study. 2015.

16. Evangelos CA, Ioanna CS ,Fotini C. Prevalence of musculoskeletal disorders in dentists. BMC Musculoskeletal Disorders20045:16

17. Tinubu BM, Mbada CE, Oyeyemi AL, Fabunmi AA. Work-Related Musculoskeletal Disorders among Nurses in 
Ibadan, South-west Nigeria: A cross-sectional. BMC Musculoskelet Disord. 2010;11:12

18. Cromie JE, Robertson VJ, Best MO. Work-Related Musculoskeletal Disorders in Physical Therapists: Prevalence, Severity, Risks, and Responses. Phys Ther. 2000;80:336-51.

19. I. Kuorinka, B. Jonsson, A. Kilbom et al., "Standardised Nordic questionnaires for the analysis of musculoskeletal symptoms," Applied Ergonomics, vol. 18, no. 3, pp. 233-237, 1987 